\title{
Battery Sizing Based on the Energy Lack and Surplus Analysis in a Stand-Alone Photovoltaic System
}

\author{
Meriem Andam 1, Jamila El Alami ${ }^{2}$, Younes Louartassi ${ }^{3}$ \\ 1,2,3 Laboratory for System Analysis, Information Processing and Integrated Management \\ (LASTIMI), High School of Technology Salé, Mohammed V University in Rabat, Morocco,
}

\begin{abstract}
The need of electricity in the world is increasing continuously, hence the emergency to resort to the exploitation of renewable energies especially for some countries like Morocco. Despite the different advantages of these energies, these are also characterized by two harmful aspects, particularly the intermittency and the difficulty of storage. In order to avoid such barriers, most researchers and industrials prefer to invest in renewable energy systems connected to the grid or other continuous energy source to meet regularly electrical needs. However, the purpose of this article is to focus on the analysis of a storage system for an off grid photovoltaic system. The goal is then to optimize the storage capacity of the installation by minimizing the oversizing which causes losses and high costs. In our article, we focused on the design of a virtual photovoltaic system located in a rural area of Errachidia in Morocco. We estimated the energy required by the load, also the necessary power of the photovoltaic field, then we estimated the Surplus and the Lack generated throughout the year based on the meteorological data of the site. Analysis of these virtual estimates can allow us to define the real required battery capacity and the appropriated number of autonomy days in order to avoid consequently oversizing.
\end{abstract}

Keywords: Photovoltaic system, Storage, Capacity, Lack, Surplus.

\section{Introduction}

Renewable energies are becoming more and more a crucial solution for different countries that are suffering from the continuous increase of energy needs, also the high dependence of other countries. Morocco is particularly characterized by several natural, geographical and climatic resources allowing it to advantageously introduce the clean and natural power production.

\subsection{Overview on the energy situation in Morocco}

Since 2009, Morocco has adopted an energy strategy that aims to increase the installed power from renewables to $52 \%$ by 2030 , including $4560 \mathrm{MW}$ in solar power, $4200 \mathrm{MW}$ in wind power 


\section{$2^{\text {nd }}$ International Conference On Innovative Research in SCIENCE ENGINEERING \& TECHNOLOGY}

and $3100 \mathrm{MW}$ in hydro power. Such strategy will also contribute to reducing the country's energy dependence to less than $82 \%$ by 2030 .

Today, the share of renewable energies is around $34 \%$ in the electricity mix and the rate of rural electrification has already reached $99.68 \%$ [1].

Following the ongoing economic development that Morocco is currently experiencing, significant electricity demand is generated and is strongly growing with an average rate of $6.5 \%$ per year [2].

The industry sector is consuming the big quantity of electricity with an average of $43.6 \%$ followed by the residential sector $(32.8 \%)$. The commercial and agricultural sector are consuming electricity with an important percentage of $22.4 \%$. The less consumer of electricity stays the transport sector [2].

The adoption of the energy strategy represented an emergency for the country especially because it suffers from a set of challenges including the dependence of fossil fuels increasing then $\mathrm{CO} 2$ emissions, the instability of the electricity system and particularly the energy dependence of other countries that exceed $96 \%$. Currently, Morocco has two interconnections with Spain and Algeria but also aims to add other new interconnexions not only with the same countries but also with other neighboring countries particularly Portugal and Mauritania [3].

\subsection{Renewable energies in Morocco}

Morocco, with its strategic geographical position, has a remarkable renewable energy potential. It is the ninth country in the world in sunshine rate: its $710000 \mathrm{~km} 2$ benefit from sunshine between 2,800 and 3,400 hours per year; the national solar technical potential is estimated at 20,000 MW. The installed power of solar in Morocco is $180 \mathrm{MW}$ in 2016.

Concerning the wind resources, the country has the world's 31 th deposit. Its $3500 \mathrm{~km}$ of Atlantic coasts record wind speeds between 7.5 and $11 \mathrm{~m} / \mathrm{s}$, the technical potential is estimated to 25,000 MW. The installed capacity of wind power in Morocco was 800 MW in 2016.

In terms of hydraulics, the dam policy has ensured the installation of $1770 \mathrm{MW}$ of power, out of a national technical potential of $3800 \mathrm{MW}$.

Exceptionally, the exploitation of the solar resources to produce electricity would allow Morocco to modify, in the long term, the composition of its energy mix [4]

In this sense and within the framework of the same national strategy, a set of projects have been implemented and others are being spread over different locations in the country: 


\section{$2^{\text {nd }}$ International Conference On Innovative Research in SCIENCE ENGINEERING \& TECHNOLOGY}

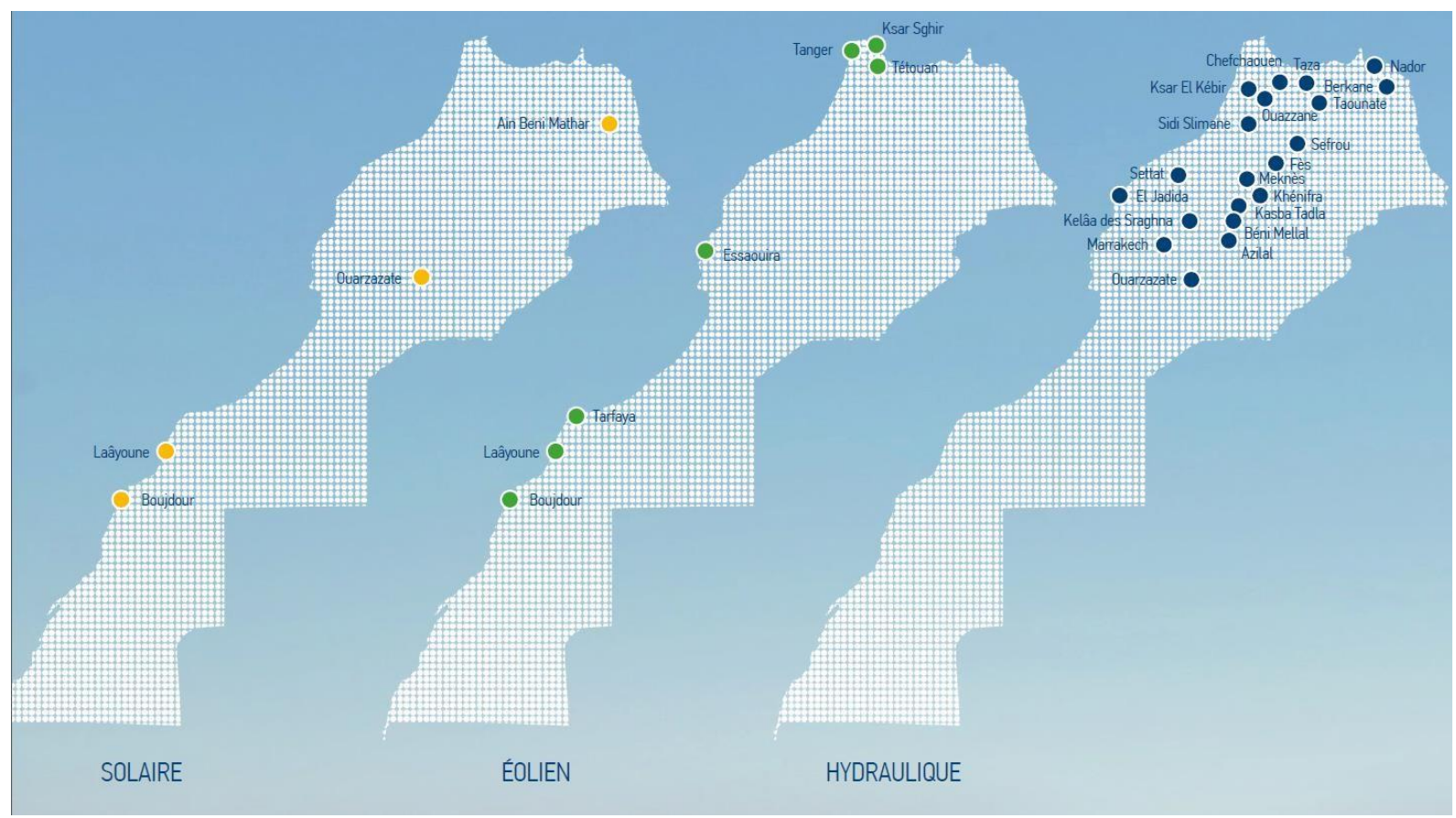

Figure 1: Overview of renewable energy projects in Morocco [4]

\subsection{Problematic}

As previously stated, Morocco has particularly different potential and significant resources in terms of renewable energy including solar energy. In this sense and following the guidelines of the national strategy, several solar stations have been set up based essentially on two main technologies the concentrated solar power plant and photovoltaic.

Solar technologies are competitive with other technologies such as wind and hydropower that require spaces and relatively substantial resources. In particular, solar photovoltaic (PV) production has increased rapidly not only in Morocco but globally, from less than one gigawatt (GW) in 2000 to around $300 \mathrm{GW}$ in 2017. Solar energy has also experienced a significant drop in cost and accelerated technological progress. The price of photovoltaic solar panels has decreased by about $80 \%$ compared to 2009 .

For this reason, we chose in our current study to be limited to solar photovoltaic since it is more accessible and easier to implement especially when we talk about small isolated and autonomous systems. The main challenge of this type of energy is storage, the objective of this article is therefore to analyze the storage system of a virtual photovoltaic installation located in Errachidia, Morocco, that is supplying the energy needs of a simple ordinary household. 


\section{$2^{\text {nd }}$ International Conference On Innovative Research in SCIENCE ENGINEERING \& TECHNOLOGY}

\section{Bibliographic Review}

The adoption of renewable energy has become a priority for economic development and urgent protection of the environment worldwide. As a result, several researches have been conducted to make their market more emergent and facilitate their introduction at a global and particular level.

Some researchers have been carried out on the production part, in particular photovoltaic, others on regulation or conversion systems, while others have opted to optimize the whole system by taking into account the communication and the interaction between the different parameters.

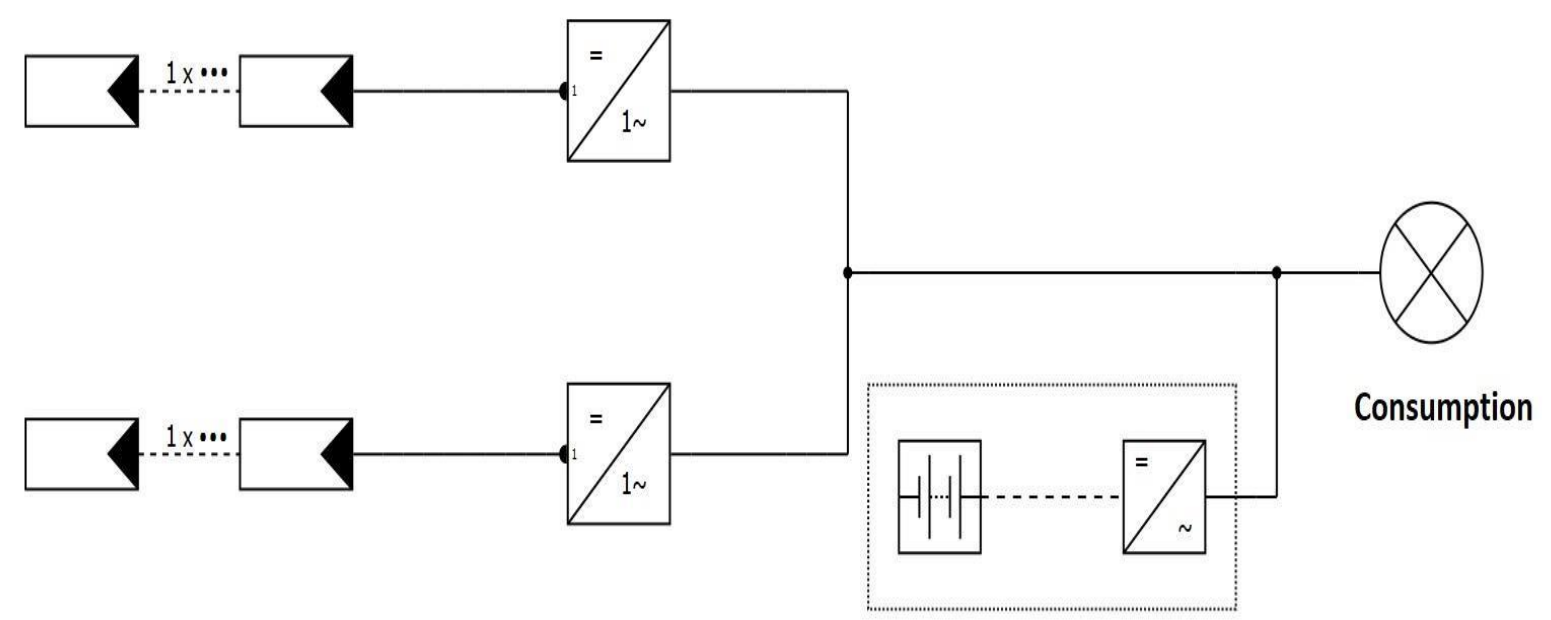

Figure 2: Overview of the stand-alone photovoltaic system (PVSOL software)

In order to design, for example, photovoltaic panels, the researchers focus on the optimization of the internal parameters of panels based on the electrical diagram of a photovoltaic cell:

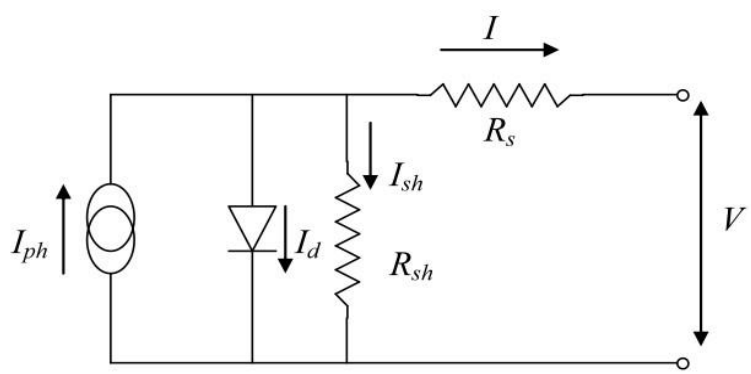

Figure 3: Equivalent diagram of a photovoltaic cell 


\section{$2^{\text {nd }}$ International Conference On Innovative Research in SCIENCE ENGINEERING \& TECHNOLOGY}

Following the formulas generated by the electrical diagram and the formulas linking the photo current Ish with external parameters including temperature and irradiation [5], it is possible to model and analyze the impact of external parameters on the power generated by the module [6].

Similarly, each of the controller and the inverter are also the subject of extensive research since the first is responsible for communicating the maximum power to the load and the second is to convert energy with minimal losses.

Energy storage is also of great interest to a group of researchers and has been treated from different points of view. Some studies have focused on identifying the best approach for energy storage for well-specified locations based on three fairly important criteria (efficiency, lifetime and cost) [7]

Other researches have focused more on the optimization of integrated storage systems in no autonomous systems connected to other energy sources, particularly the network, by analyzing a set of technical and economic parameters [8].

\section{Sizing of photovoltaic standalone system}

\subsection{Virtual photovoltaic system}

In our study, we chose to start by identifying a virtual photovoltaic system, hence the need to be informed of the potential for existing solar energy in Morocco and preferably choose the location characterized by a significant potential solar radiation.

Researches have been conducted to define the potential of Morocco for the introduction of solar systems according to a set of criteria such as Climate, Orography, Water resource and Location [9] and the results showed that Morocco has great potential for two technologies CSP and PV especially in the South region.

M. Azeroual et al. [2] have even go further in forecasting the solar potential for the year 2030. As a result, and taking into consideration the planned projects, those in progress and the forecasts of the high demand due to the economic and industrial development of the country, Morocco is well positioned to achieve its objectives for 2030. Concretely, the forecast has shown that the available capacity of solar energy is 4713MW towards 2030.

In our study, we chose to associate our autonomous photovoltaic installation with the region of Errachidia as it is among the regions that are characterized by a significant and appropriate solar potential. 


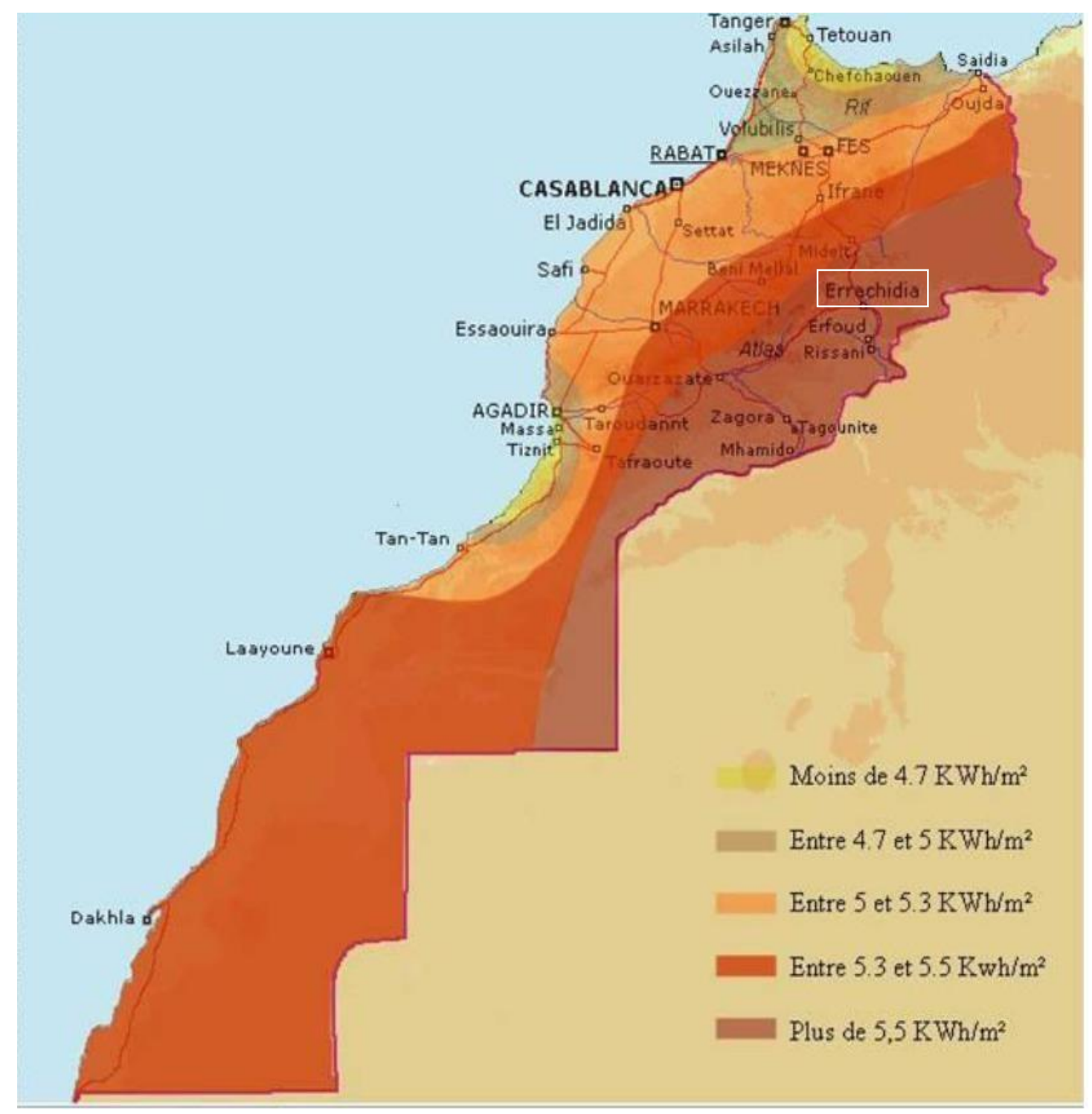

Figure 4 : carte d'irradiation solaire au Maroc [ 10 ]

At this stage, the nature of our installation will represent only a basic tool to analyze the operation of the storage system, so we will be limited to an installation intended to supply the needs of a representative household in a rural area of Errachidia. It is thus essential to determine the metrological characteristics of the chosen virtual zone: 


\section{$2^{\text {nd }}$ International Conference On \\ Innovative Research in \\ SCIENCE ENGINEERING \& TECHNOLOGY}

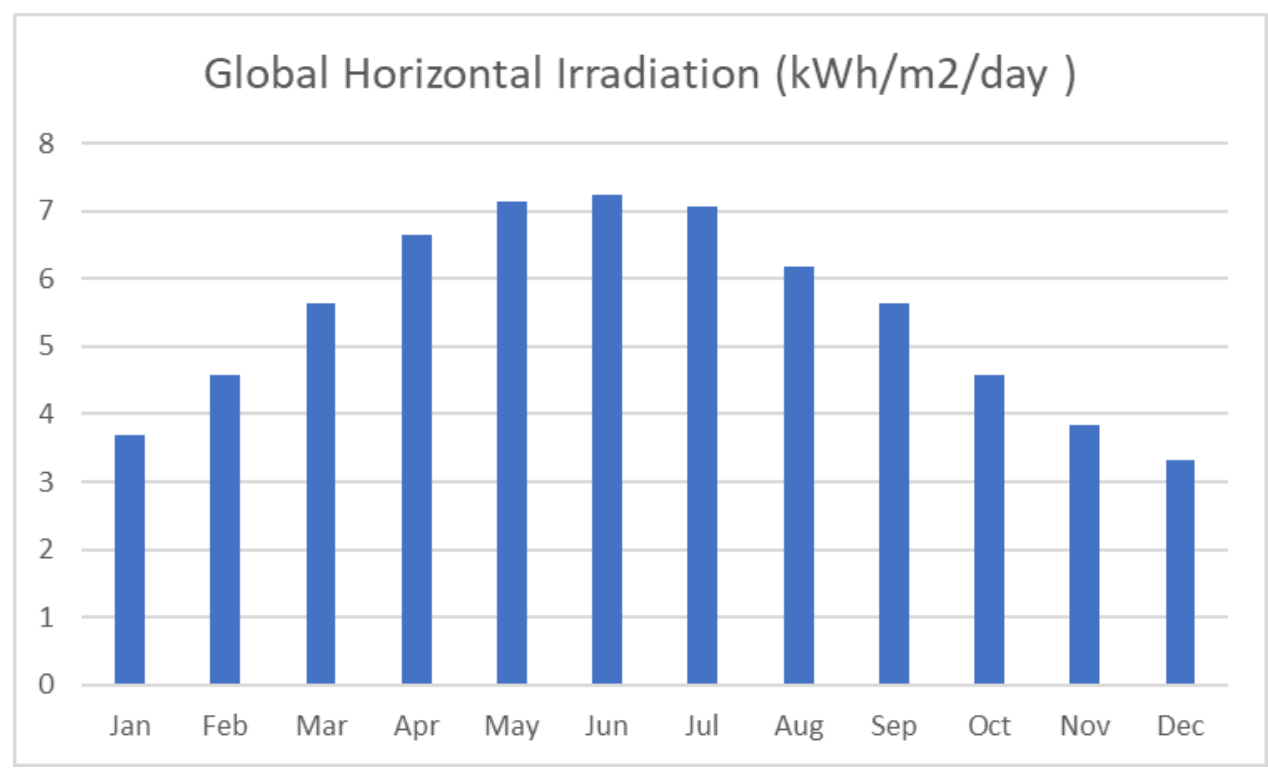

\subsection{Definition of the energy required}

As part of the program for widespread rural electrification (PERG) which has allowed since its establishment in 1996 until the end of October 2018, to connect 44,001 villages to the national electricity grid, providing then 2.173.509 housing units in electricity and 19.438 housing unit in individual photovoltaic panels [Ministry of Energy, Mines and Sustainable Development], only $1 \%$ of households in rural areas have requested photovoltaic kits with a capacity of $200 \mathrm{wc}$ and the rest have been equipped with photovoltaic kits of about $75 \mathrm{wc}$ per household and this case in the absence of a refrigerator. Nevertheless, the study has shown that to reach a satisfactory standard of living, the power required is around $0.26 \mathrm{kwc}$ [10]. In our case and for an isolated rural system in Errachidia, the needs estimate is shown in the following table:

Table 1: Estimation of the load

\begin{tabular}{|l|l|l|l|l|l|}
\hline Equipement in Use & $\begin{array}{c}\text { No. of } \\
\text { equipments }\end{array}$ & $\begin{array}{c}\text { Power of } \\
\text { equipment }\end{array}$ & $\begin{array}{c}\text { Total wattage } \\
(\mathrm{w})\end{array}$ & $\begin{array}{c}\text { Daily } \\
\text { appliances } \\
\text { use (h) }\end{array}$ & $\begin{array}{c}\text { Daily energy } \\
\text { required (wh /d) }\end{array}$ \\
\hline Lamps & 4 & 25 & 100 & 6 & 600 \\
\hline Refrigerator & 1 & 100 & 100 & 24 & 2400 \\
\hline TV & 1 & 100 & 100 & 6 & 600 \\
\hline Fans & 3 & 75 & 225 & 3 & 675 \\
\hline
\end{tabular}




\section{$2^{\text {nd }}$ International Conference On Innovative Research in SCIENCE ENGINEERING \& TECHNOLOGY}

\subsection{Sizing the photovoltaic field}

In order to determine the importance of autonomous photovoltaic installations for the electrification of isolated rural areas, a set of research studies have been carried out, for example A. Ghafoor et al. [11] first established a model of an off grid PV installation by dimensioning the various components including photovoltaic field, batteries, regulator and inverter to then develop a study and analyzes using life cycle cost method that proved that the Off PV electricity is technically and economically competitive especially for the electrification of residential applications. In our case, we will limit ourselves to the identification of the necessary photovoltaic field and the capacity of the battery because our current objective is to analyze the viability of the storage system.

The size of the PV field can be determined based on the following formula:

$$
\mathrm{Pwc}=\frac{E n}{\operatorname{Havg} * K}
$$

Pwc: Photovoltaic power (wc)

En: Energy needed by the load (wh/day)

Havg: Avairage irradiation available per day $(\mathrm{kWh} / \mathrm{m} 2 / \mathrm{d})$

$\mathbf{K}$ : Correcting coefficient which takes into account a set of parameters such as the performance of the various components of the installation. For battery systems, $\mathrm{K}$ is between 0.55 and 0.75 .

\subsection{Lack and Surplus}

Depending on the solar irradiation of each month, the energy provided by the photovoltaic field varies as shown below:

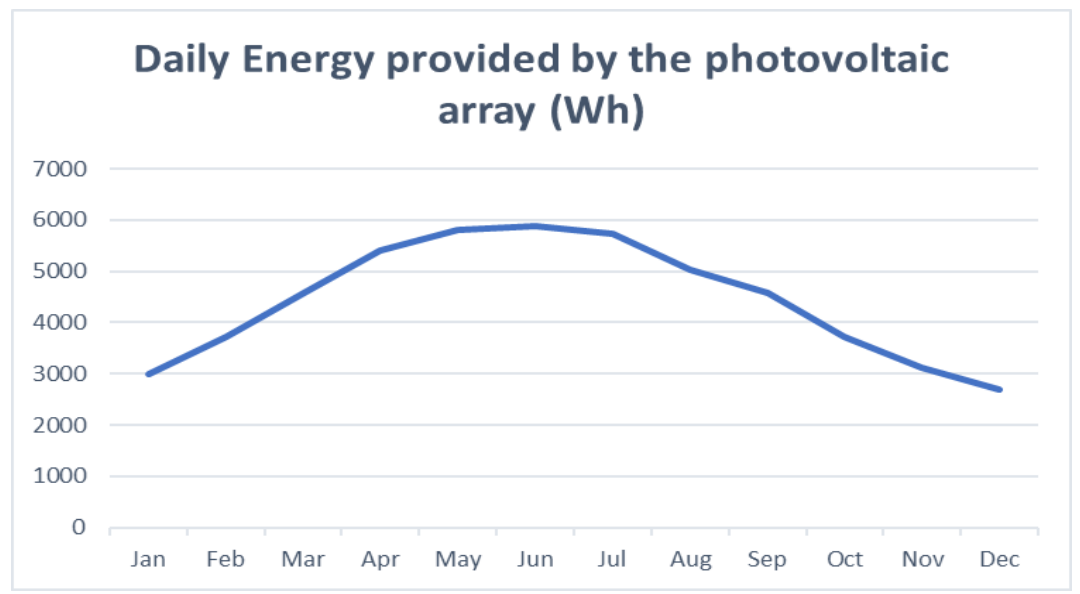

This variation generates Surpluses and Lacks at the installation level. According to the solar data, the energy (wh) provided by the photovoltaic field to the battery also varies depending on the months. Following an estimate of the need of the day $(\mathrm{Bd})$ and the need of the night $(\mathrm{Bn})$, 


\section{$2^{\text {nd }}$ International Conference On Innovative Research in SCIENCE ENGINEERING \& TECHNOLOGY}

we noticed that the photovoltaic field meets the estimated needs of the day with intermittent surplus. By cons, the night needs are exposed to Lack and Surplus in terms of energy. The energy provided by the battery thus varies from a minimum to a maximum as follows:

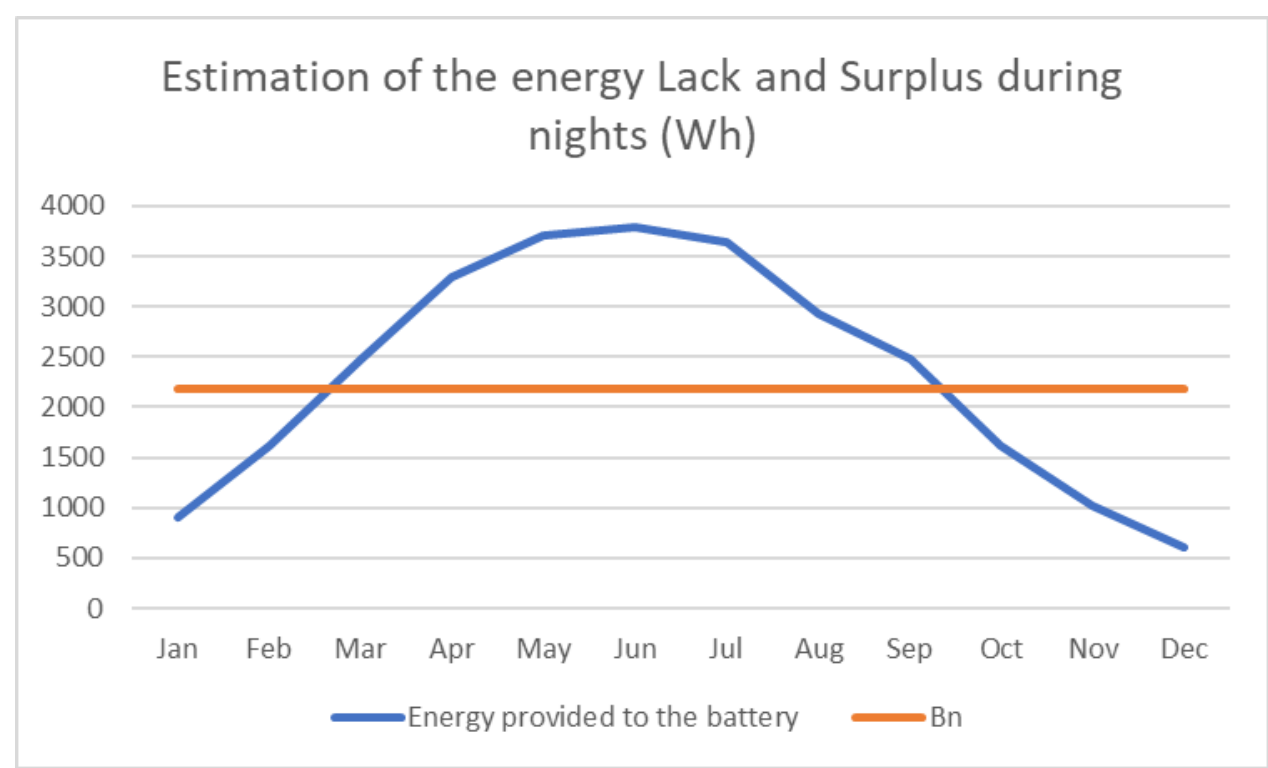

According to the analysis of the surplus and Lack values corresponding to our photovoltaic installation, the maximum energy of the battery must support the maximum surplus, also the number of autonomy days and the depth of discharge must be chosen upstream to avoid oversizing the battery which generates substantial costs. Thus, the capacity of the battery should not be dimensioned without considering the estimates of surplus and Lack throughout the year. In our case, the impact of the Lack was not considered as the battery in Errachidia climatic conditions will feed the load approximately during the day.

\section{Conclusion}

Following the analysis of the operation of this virtual installation in Errachidia, we first established an analysis of energy consumption and also meteorological data relevant to a household located in Errachidia (one of the sunniest regions in Morocco). Then, it was necessary to size the power of the photovoltaic field (wc) and define the actual needs by separating the needs of the day mainly provided by the photovoltaic panels and the needs of the night powered by the battery. As a result, and taking into account the importance of maintaining a large depth of discharge, the battery will only have to withstand the maximum surpluses with some overshoots and therefore the choice of the number of autonomy days must be defined on the basis of similar analyzes. Our study focused on a virtual analysis but in our next work, we plan to validate our hypothesis with experimentation or real theoretical simulation. 


\section{$2^{\text {nd }}$ International Conference On Innovative Research in SCIENCE ENGINEERING \& TECHNOLOGY}

\section{References}

[1] M. Ghazali, Secretary General of the Ministry of Energy, Mines and Sustainable Development, , (2019), Africa Energy Forum, Lisbon, Portugal.

[2] M. Azeroual, A. El Makrini , H. El Moussaoui, H. El Markhi , (2018 ), Renewable Energy Potential and Available Capacity for wind and solar Power in Morocco Towards 2030 , Journal of Engineering Science ans Technology Review .

[3] MEMEE (2016). Regional integration strategic choice of Morocco: Strengthening and development of energy interconnection with neighboring countries. Available: http://www.mem.gov.ma/SitePages/CP2016/CP09Juin16.aspx,

[4] Moroccan Agency for Sustainable Energy, Available: http://www.energiesrenouvelables.ma/

[5] A. Ould Mohamed Yahya , A. Ould Mahmoud et I. Youm, (2007),Modélisation d'un système de stockage intégré dans un système hybride (PV / Eolien / Diesel),Revue des Energies Renouvelables Vol .10 N² 205-214.

[6] Vinod, Raj Kumar, S.K. Singh, (2018), Solar photovoltaic modeling and simulation: As a renewable energy solution, Energy Reports 701-712.

[7] F. Rahman, S. Rehman, M. Arif Abdul-Majeed, (2012), Overview of energy storage systems for storing electricity from renewable energy sources in Saudi Arabia, Renewable and Sustainable Energy Reviews 16, 274-283.

[8] L. Bridier, (2016), Modeling and optimization of a storage system coupled with intermittent renewable electricity production, $\mathrm{PhD}$ Thesis, University of Réunion, France .

[9] G Tazi, O Jbaihi, A Ghennioui, A Alami Merrouni, M Bakkali, (2018), Estimating the Renewable Energy Potential in Morocco: solar energy as a case study, IOP Conference Series: Earth and Environmental Science.

[10] Étude du potentiel de développement de l'énergie photovoltaïque dans les régions de Meknès-Tafilalet, Oriental et Souss-Massa-Drâa, Giz, (2011).

[11] A. Ghafoor, A. Munir, (2015), Design and economics analysis of an off-grid PV system for household electrification, Renewable and Sustainable Energy Reviews, 42, 496-502 . 